\title{
Exploring PubMed as a reliable resource for scholarly communications services
}

\author{
Peace Ossom Williamson, MLS, MS, AHIP; Christian I. J. Minter, MSLIS
}

See end of article for authors' affiliations.

\begin{abstract}
Objective: PubMed's provision of MEDLINE and other National Library of Medicine (NLM) resources has made it one of the most widely accessible biomedical resources globally. The growth of PubMed Central (PMC) and public access mandates have affected PubMed's composition. The authors tested recent claims that content in PMC is of low quality and affects PubMed's reliability, while exploring PubMed's role in the current scholarly communications landscape.
\end{abstract}

Methods: The percentage of MEDLINE-indexed records was assessed in PubMed and various subsets of records from PMC. Data were retrieved via the National Center for Biotechnology Information (NCBI) interface, and follow-up interviews with a PMC external reviewer and staff at NLM were conducted.

Results: Almost all PubMed content (91\%) is indexed in MEDLINE; however, since the launch of PMC, the percentage of PubMed records indexed in MEDLINE has slowly decreased. This trend is the result of an increase in PMC content from journals that are not indexed in MEDLINE and not a result of author manuscripts submitted to PMC in compliance with public access policies. Author manuscripts in PMC continue to be published in MEDLINE-indexed journals at a high rate (85\%). The interviewees clarified the difference between the sources, with MEDLINE serving as a highly selective index of journals in biomedical literature and PMC serving as an open archive of quality biomedical and life sciences literature and a repository of funded research.

Conclusion: The differing scopes of PMC and MEDLINE will likely continue to affect their overlap; however, quality control exists in the maintenance and facilitation of both resources, and funding from major grantors is a major component of quality assurance in PMC.

This article has been approved for the Medical Library Association's Independent Reading Program <http://www.mlanet.org/page/independent-reading-program>.

See end of article for supplemental content.

\section{INTRODUCTION}

The National Library of Medicine (NLM) creates and maintains resources that are at the heart of library services relating to health information. NLM's mission has always included a focus on supporting health care research and practice and providing access to trustworthy and timely health information [1]. When NLM expanded its reach through online services, its feature product, MEDLINE, continued in that tradition. PubMed delivers a publicly available search interface for MEDLINE as well as other NLM resources, making it the premier source for biomedical literature and one of the most widely accessible resources in the world. Health sciences practitioners, researchers, faculty, and students have repeatedly reported PubMed and MEDLINE as one of the few sources they use to search literature [2-5].

As research, publishing, and access to scholarly resources have evolved over recent years, it is important to determine the role that PubMed and other NLM resources play in the dissemination of research and other scholarly output. Librarians are 
increasingly expected to assist with research and publishing issues, including ensuring funding compliance, conducting literature reviews, navigating open access, understanding copyright, measuring impact, working with data, and disseminating research $[6,7]$. As a result, medical librarians and researchers depend on NLM resources as trustworthy sources of quality literature.

\section{About PubMed, MEDLINE, and PubMed Central}

For many users, PubMed is synonymous with the MEDLINE database. In 1971, NLM created MEDLINE to serve as the online version of the Medical Literature Analysis and Retrieval System (MEDLARS). MEDLINE (or MEDLARS online) consists of life sciences and biomedical journal citations that are indexed with NLM Medical Subject Headings (MeSH) [8]. Originally, the MEDLINE service could only support up to twenty-five users simultaneously, and access was available primarily in medical libraries [9]. To improve the availability of MEDLINE, NLM released the PubMed search engine as part of the Entrez retrieval system, beginning as an experimental database in 1996 [10].

As of June 1997, PubMed provides free and unlimited access for all users through the Internet [11]. Over time, PubMed became more than a public interface for MEDLINE citations and publisher links to full-text: it has undergone numerous transformations to improve usability and functionality through several redesigns, and introduced features including LinkOut and Single
Citation Matcher [12]. PubMed has also provided a pathway toward increased accessibility to research by expanding to include access to PubMed Central and the National Center for Biotechnology Information (NCBI) Bookshelf [13-15].

As of October 2017, PubMed contained 27.5 million records, representing approximately 7,000 journals [16]. Together, records from PubMed Central (PMC) and records included in or marked for inclusion in MEDLINE make up almost $95 \%$ of PubMed (Figure 1). Bookshelf is approximately 1\% of PubMed, and the remaining $4 \%$ consists of several types of records, including out-of-scope citations from MEDLINE journals, citations that precede the date that a journal is selected for MEDLINE, and new records submitted by publishers that have not yet been reviewed by NLM staff.

The largest percentage of records in PubMed comes from MEDLINE, and the Literature Selection Technical Review Committee (LSTRC) is responsible for reviewing and recommending journal titles to include in MEDLINE. LSTRC assesses the scope, quality of content, accessibility of foreign-language articles, technical quality, and publishing practices. Also, "journals must be able to submit XML tagged data, and electronic-only journals must provide robust current access to all of its content and have an acceptable arrangement for permanent preservation of, and access to, the content" [17]. Subject expertise and relevance are additional criteria. At least $20 \%$ of content must relate to biomedicine and health, and journals that are accepted are oriented toward original research and provide the highest expertise

Figure 1 Composition of PubMed in 2017

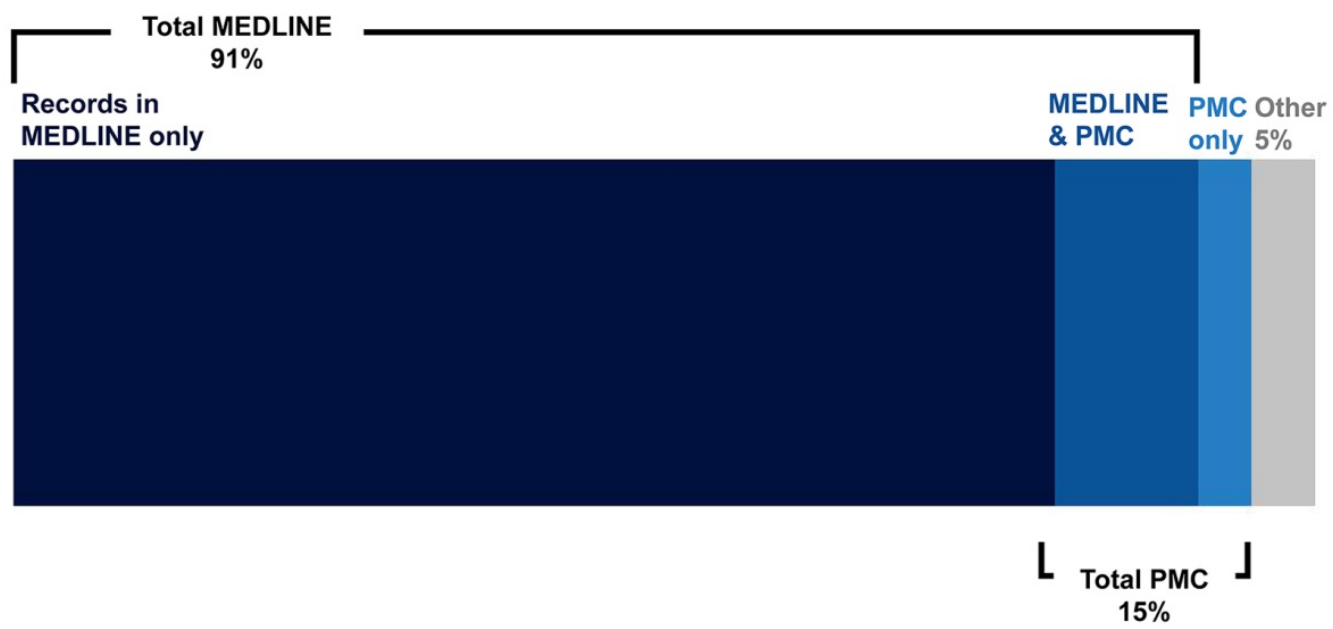


in the field. Rejected journals can reapply after 2 years. If rejected after a second submission, journals can then reapply every 3 years [16-18]. As of October 2017, MEDLINE contained 25 million records from over 5,600 journals [16].

The second largest component of PubMed is PMC. Launched in 2000, PMC serves as a permanent digital archive of full-text life sciences and biomedical journal articles. PMC also includes articles deposited by journal publishers and "author manuscripts," in other words, published articles that are submitted in compliance with the public access policies of the National Institutes of Health (NIH) and other research funding agencies [15, 19-21]. NLM provides public access to the contents of PMC and manages a collaborative called PMC International to store copies of its contents in local deposits at centers in multiple global locations [15, 22]. Publishers supply $88 \%$ of the content in PMC through active provision of current or historical content or through selective deposits, and the remaining $12 \%$ of PMC comes from author manuscripts. As of October 2017, PMC contained 4.5 million articles.

Publishers submit an application and sign an agreement to participate in PMC, and there are different options for contributing content (Figure 2). Journals that agree to full participation deposit their entire issues in the archive on an ongoing basis and account for more than half of PMC. Scanned historical content represents $28 \%$ of the content and includes back issues of biomedical journals that NLM has identified as having historical significance. Selective deposits account for $5 \%$ of the content and include open access articles from hybrid publishers and articles deposited to support specific funding agency policies. As of May 2018, selective deposit is limited to journals indexed in MEDLINE [16, 17, 23].
NLM staff review journals prior to including them to determine if they meet the criteria of the Collection Development Manual, which specifies the aim to acquire primarily scholarly literature "pertaining to health care, to the practice of the science and art of medicine broadly conceived, and to those branches of the life sciences which are fundamental to that science and art" $[15,24]$. An external panel of independent experts assesses the journal's scientific, editorial, and technical quality, and the NLM Library Operations Division makes the final decision. This process was implemented in 2014 following the approval of the PMC National Advisory Committee because of a significant increase in journals applying to participate. Rejected journals can reapply after two years $[16,25,26]$.

PMC is also the designated repository for twelve US agencies and organizations and twenty-seven European funders [16, 21]. Author manuscripts are deposited in compliance with these and other funders' public access policies. The policies require that literature resulting from specified funded research must be made available in PMC within six to twelve months of publication, depending on the funder policy $[19,20]$. The manuscripts are distinguishable from other content by the author manuscript banner and runner down the left side of the page.

Other NLM resources that may be associated with PubMed are the NLM Catalog, PubMed Health, and MedlinePlus. The NLM Catalog contains bibliographic records for over 1.4 million journals, books, audiovisuals, electronic resources, and other materials. It also includes detailed indexing information for journals in PubMed and other NCBI databases, but not all materials in the NLM Catalog are part of NLM's collection [16]. While PubMed Health and MedlinePlus have

Figure 2 Composition of PubMed Central in 2017

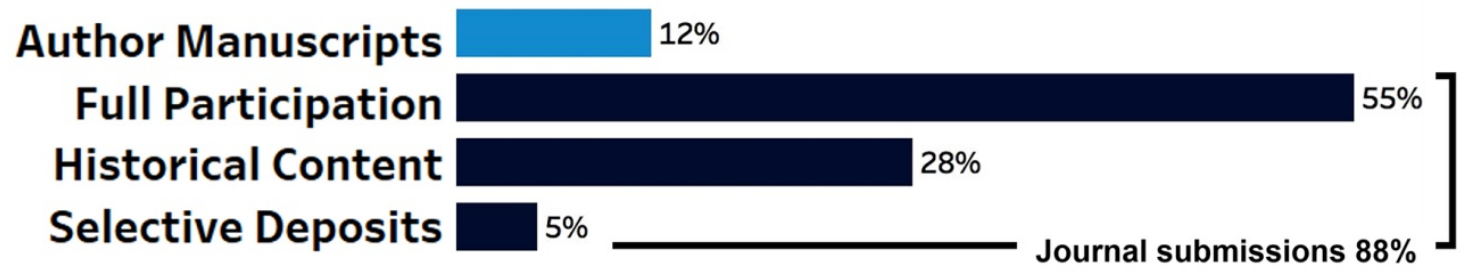


similar names to the aforementioned resources, these resources are built for different uses: PubMed Health provides reviews of clinical effectiveness research for health care providers and patients and will be retired in 2018, and MedlinePlus is a consumer health website providing information on various health topics, drugs, dietary supplements, and health tools [27, 28].

\section{Scholarly communication uses of PubMed, MEDLINE, and PubMed Central}

As librarians respond to the growing demand for knowledge and expertise about publishing, author rights, and access, PubMed has served as a resource for supporting these services. Authors are looking at options for open and public access to their research, and a 2013 memorandum from the US Office of Science and Technology Policy (OSTP) provided greater motivation for increasing research availability. The OSTP memorandum instructed federal agencies with more than $\$ 100$ million in annual research expenditures to consult with stakeholders and implement a plan for public access within 6 months [29]. Thus, many authors must now comply with open and public access mandates from publishers and funders, many of which resulted from the 2013 OSTP memorandum.

Navigating the publishing process through the proliferation of predatory publishers adds another challenge for authors [30]. Authors are increasingly turning to libraries for information that will guide them through the research and publishing process. Advisory organizations are also recommending the library as a resource. For example, the Federal Trade Commission (FTC) recommends checking with a librarian before submitting an article to a journal to avoid predatory publishers [31]. NIH supported the FTC's recommendations in a November 2017 notice that provided advice for authors who are publishing the results of NIH-funded research. This statement provides recommendations for identifying credible journals and implores its stakeholders (including librarians) to help authors engage in effective scholarly communication practices. NIH also recognizes the role of NLM in maintaining PubMed and PMC and encouraging publishers to follow established industry best practices [32].

Publishers, librarians, and authors rely on PubMed/MEDLINE, among other resources, as a vetting tool. For publishers, having a journal indexed in MEDLINE means that it has met stringent criteria for quality - which attracts potential authors, subscribers, and readers - and journals receive more submissions after their acceptance into MEDLINE. Publishers also value the $\mathrm{MeSH}$ metadata and the increased discoverability through PubMed or private vendors that provide access [21]. MEDLINE is an important tool for librarians to help users find trustworthy journals in which to publish. In addition, authors who publish in MEDLINE-indexed journals can often reach a larger audience due to health professionals' and medical librarians' preference for PubMed and MEDLINE to search for literature.

PMC also contributes to scholarly communication efforts because it provides public access to research. Funders support this archive because research resulting from public funding should be available to the public [29, 33]. Providing easier access also helps to translate research into practice. Evidence-based practice can be inhibited when practitioners are unable to access research behind paywalls. Public and open access can also improve the likelihood of an author's work being cited and can benefit the teaching, collaboration, and implementation of research [29, 34-36]. Materials do not have to be open access to be included in PMC, and most materials that are currently available are under copyright. Librarians and researchers using materials found in the archive must still comply with the articles' copyright and license terms.

There has been some concern about the quality of PubMed content from sources other than MEDLINE. Some of this concern comes from a misunderstanding of the different components of PubMed. That is, although comparisons are often made between PubMed and MEDLINE as if they are two different databases, MEDLINE is in fact a subset of PubMed. There has also been misrepresentation that PubMed is an index itself $[37,38]$. The main focus of this concern centers on the inclusion of journals in PubMed that were identified by Jeffrey Beall on his list of "potentially predatory publishers," which is no longer updated and is archived at beallslist.weebly.com.

Other concern centers on PMC as affecting PubMed's quality, particularly author manuscripts that are deposited into PMC and automatically included in PubMed without any review process. There are also criticisms that the PMC inclusion 
criteria for participating journals are less stringent than MEDLINE inclusion criteria [39, 40], although author manuscripts are peer-reviewed manuscripts that have been accepted for publication and deposited in compliance with a funder's policy; some refer to this as the "PMC backdoor." One author states, "PubMed's brand has long been muddled in ways that pass lower-quality works through the system under cover of prestige. This has real consequences" [39]. This argument exists largely on the assumption that lower-quality publications as opposed to journals reviewed and included in MEDLINE - are increasingly found in PubMed due to NIH-funded research published in journals managed by predatory publishers.

The authors did not investigate the first concern regarding the percentage of "predatory publishers" in PubMed because it centers on a list that is highly disputed as reputable [41]. Furthermore, publishing in a potentially predatory publication does not automatically equate to poor scientific methods in an article, and when articles from publications in Beall's List were assessed recently, PMC and PubMed were found to have lower numbers of these articles than resources like Scopus and Google Scholar [42].

Our aim was to examine whether there has been a change in the proportion of PubMed content indexed in MEDLINE, and if so, whether PMC is contributing to this shift. We also examined whether the deposit of author manuscripts provides a "PMC backdoor" for low-quality research. In addition, we interviewed representatives speaking on behalf of NLM and an expert consultant for the PMC journal review process to provide context regarding the history, purpose, and quality control of these resources.

\section{METHODS}

We collected data in November 2017 through searches via the PubMed interface along with calculations in Excel. Data were obtained and organized according to the year that records were created in PubMed to show the trend in items added to PubMed each year. Data were not organized by publication year because records are not always added to PubMed in the same year that they are published. PMC records were also retrieved by searching PubMed using the subset pubmed pmc[sb], which retrieves live or available journal article records in PMC (i.e., excluding articles currently under embargo).

Because PubMed provides a public access interface for MEDLINE, we investigated current practices relating to the addition of records in PubMed to examine whether MEDLINE-indexed articles continue to represent the majority of PubMed records. To do this, we obtained the number of new records added to PubMed in 1990 and to both PubMed and PMC for the years 2000 to 2017. We also obtained the number of new records that were indexed in MEDLINE and still in-process to be indexed in MEDLINE during the same time span in order to determine the ongoing percentage of records in each resource that is or will be indexed in MEDLINE.

For the purpose of our analysis, MEDLINE records included the records in PubMed marked as either medline or inprocess in the subset field. The subset field retrieves records by citation status, subject, or journal category, with the search tag [SB] [43]. The records marked as medline have been indexed with $\mathrm{MeSH}$ and, if relevant, may be linked to the NCBI Gene database or included in Supplementary Concept Records for substances that are not in MeSH [44, 45]. The in-process records have been identified for inclusion in MEDLINE, but the indexing process is not completed yet; therefore, any records with the inprocess subset would be missed if a user searches PubMed using only MeSH (or any MEDLINE-only interface).

Data were collected on the number of author manuscript records in PMC from 2005 to 2017 along with the number of these records that were also indexed in MEDLINE to determine the percentage of PMC content that was author manuscripts and the percentage of author manuscripts that was indexed in MEDLINE in recent years. All trends were compared prior to and following the NIH public access mandate to determine whether the mandate served as a motivation for authors to deposit their articles and for journals to participate in PMC to attract potential authors' submissions.

Using an adaptation of the Comparing Means and Proportions spreadsheet created by Princeton Data and Statistical Services, we performed descriptive analysis of trends via $z$-test across years, with a significance threshold of $a=0.001$.

Supplementary calculations were made in Tableau Desktop 10.1.1 to create figures. Supplemental 
Appendix A provides the formulas we used to perform the statistical analyses.

We also interviewed Joyce E. B. Backus, NLM associate director for library operations; Kathryn Funk, NLM program manager for PMC; and Laurey Steinke, an expert consultant for the PMC journal review process and assistant professor at the University of Nebraska Medical Center Department of Biochemistry and Molecular Biology, for additional qualitative details regarding PubMed, MEDLINE, and PMC. Deborah Ozga, NLM head of the Index Section, and Rebecca Stanger, NLM journal publisher liaison, provided additional information via email.

\section{RESULTS}

PubMed remains primarily composed of MEDLINE records, but this composition has changed slowly over time. We can see this in the past decade: $96 \%$ of PubMed consisted of MEDLINE records in 2008, whereas $91 \%$ of PubMed consisted of MEDLINE records (including in-process records) in 2017. The cause of the overall composition shift was evident when we investigated the records that were added each year to determine the percentage that were indexed in MEDLINE, in process to be indexed in MEDLINE, and not indexed in MEDLINE. In both PubMed and PMC, records outside of MEDLINE composed a larger percentage of new records each year (Figure 3).

\section{PubMed's growth and backlog}

The number of records added to PubMed and PMC increased between 2000 and 2017 (Figure 4). Not surprisingly, there was a jump in new PMC records following the $2008 \mathrm{NIH}$ public access mandate.

In November 2017, over 800,000 new PubMed records that had been created between 2011 to 2017 were still in-process and not yet indexed in MEDLINE. More than 265,000 and 506,000 of these new records were created in 2016 and 2017, respectively. In her email correspondence, Ozga acknowledged a backlog and mentioned that NLM is working toward developing variations of the Medical Text Indexer (MTI) algorithm, such as the MTI First Line Indexing, for semi-automated or fully automated indexing to reduce the backlog of inprocess records $[13,34]$.

Figure 3 MEDLINE-indexing of new records in PubMed and PMC by year

Key: Indexed in MEDLINE In Process for MEDLINE Not In MEDLINE

\section{PubMed}

\begin{tabular}{|l|c|c|c|}
\hline 2008 & $92 \%$ & $8 \%$ \\
\hline 2012 & & $86 \%$ & $14 \%$ \\
2016 & & $23 \%$ & $21 \%$ \\
2017 & $20 \%$ & $46 \%$ & $34 \%$ \\
\hline
\end{tabular}

\section{PMC}

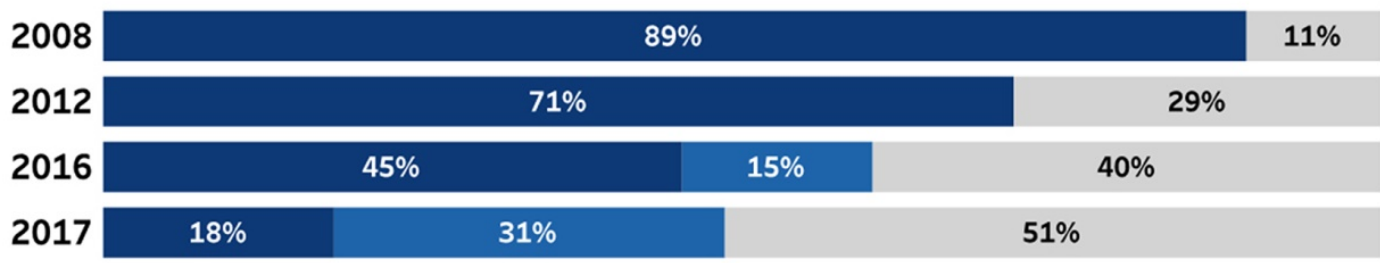


DOI: dx.doi.org/10.5195/jmla.2019.433

Figure 4 New PubMed and PMC records added by year (by 10,000s)

PubMed

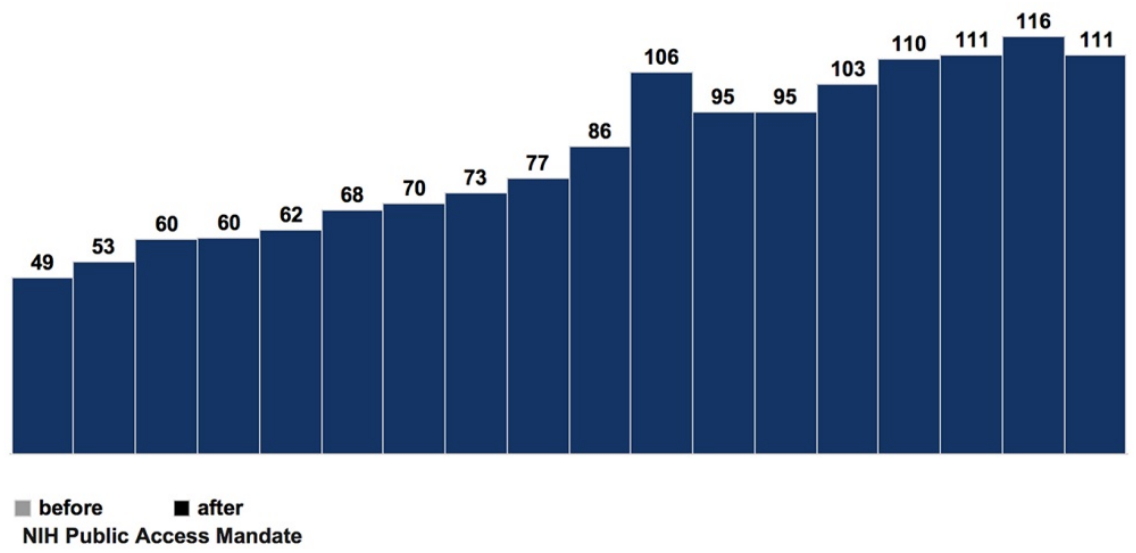

PMC

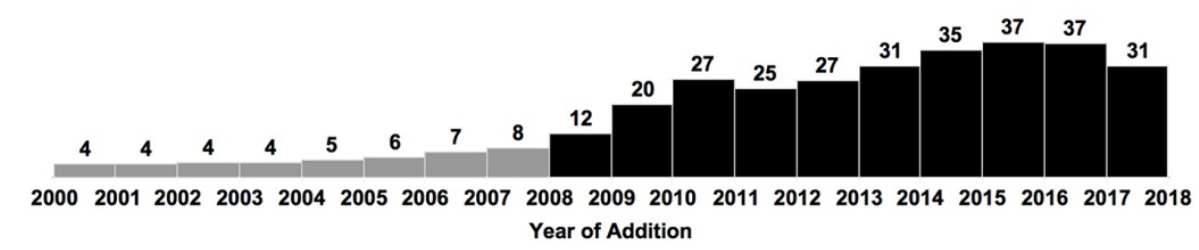

\section{MEDLINE representation in PubMed}

We obtained the number of new records added to PubMed in 1990 and to both PubMed and PMC for the years 2000 to 2017. Although the proportion of new PubMed and PMC records that were indexed in MEDLINE varied across years, a pronounced change in the proportion of MEDLINE-indexed PMC records was observed after the NIH public access mandate went into effect in 2008, whereas the trend in PubMed records was similar but less extreme (Figure 5). It is important to note that PMC records are a subset of PubMed records.

Bonferroni-adjusted $p$-values showed that the proportion of MEDLINE-indexed records differed significantly between PubMed and PMC $(p<0.001)$. We also tested the proportion of new PubMed and PMC records across years to identify trends in their MEDLINE indexing. New PubMed records were compared between 1990 (10 years before PMC), 2000 (at PMC's start), and 2008-2017 (in the past decade). New PMC records were compared between 2000 and 2008-2017. The proportion of new MEDLINEindexed PubMed records (out of total records) differed significantly across all year comparisons $(p<0.001)$, except for between 2010 and 2014 $(p>0.001)$. The proportion of new MEDLINEindexed PMC records also differed significantly across years $(p<0.001)$, except for between 2009 and 2014 ( $p>0.001)$ and between 2012 and 2013 ( $p>0.001)$.

We next examined the number of new records for author manuscripts in PMC from 2005 to 2017 to look at trends of publication in MEDLINE journals. Before the NIH public access mandate in 2008, almost all author manuscripts in PMC were published in MEDLINE-indexed journals. From 2005 to 2011, author manuscripts were submitted at an increasing rate, and, as of 2017, more than twothirds of these records were still published in MEDLINE-indexed journals (Figure 6). Although they are called "author manuscripts," Funk stated that over $70 \%$ of the manuscript submitted to the NIH Manuscript Submission System (NIHMS) were publisher-initiated to help authors comply with the NIH public access policy [25]. Even though more manuscripts were being deposited to comply with public access policies, these submissions were still only $12 \%$ of PMC and were an even smaller component of PubMed (<2\%). 
Figure 5 Percentage of new PubMed and PMC records indexed in MEDLINE

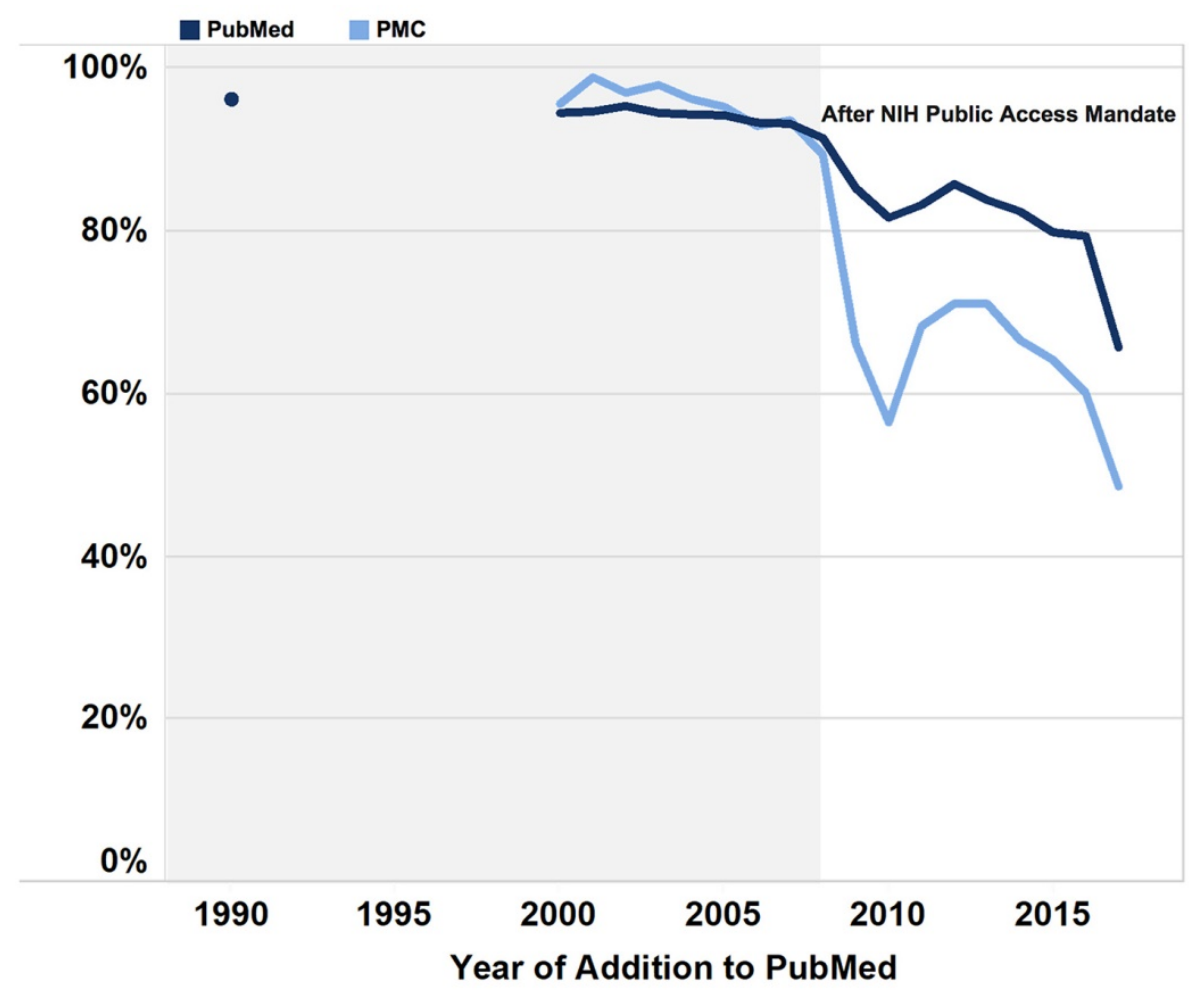

Figure 6 New author manuscript records added to PubMed

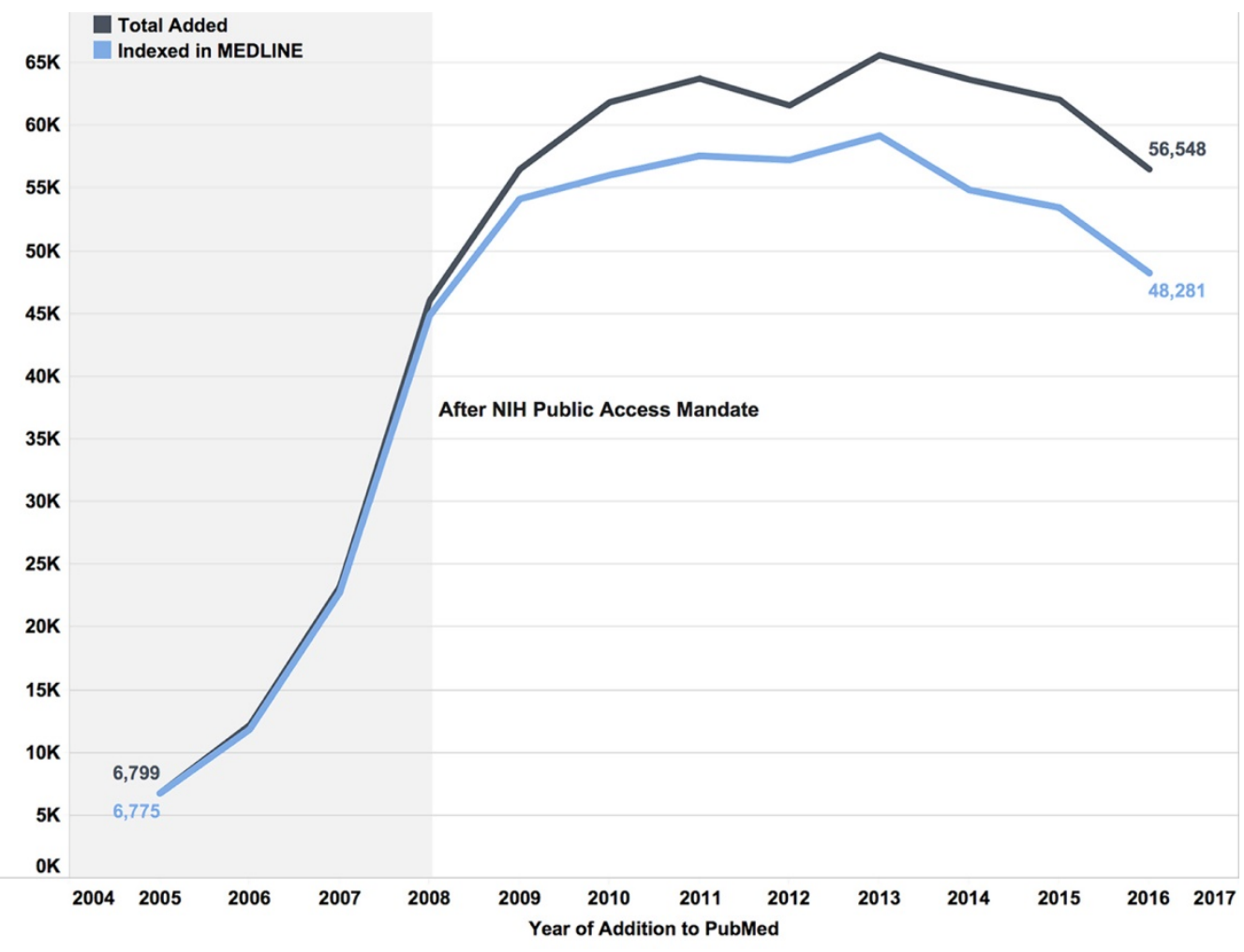


While funding mandates dictate deposit and PMC author manuscripts are automatically included in PubMed, NLM staff added by email that "NIH and other funders do not dictate the journals in which their funded authors may publish. Consequently, author manuscripts in PMC may be from journals that have not yet undergone scientific review by NLM, are traditionally out of scope for the NLM collection, or have not met NLM's standards for PMC" [17].

We also examined the number of PMC records from publishers that deposited either entire issues through full participation or selective deposit of materials that are not related to compliance with public access policies. This represents approximately $83 \%$ of PMC and has undergone the largest change in MEDLINE indexing over time. We excluded author manuscript records from this search. After the NIH public access mandate took effect in 2008, the number of new publisher-submitted records added to PMC doubled, and the number of new publisher-submitted, MEDLINE-indexed records dropped by half (Figure 7).
When asked about the changing percentage of new records indexed in MEDLINE, Backus stated that although NLM's aim is not to maintain a certain proportion of MEDLINE records in PubMed or PMC, there is hope that more MEDLINE-indexed journals will be deposited in PMC for long-term preservation and broader access [18]. Backus also noted that it is important to understand the different aims of MEDLINE and PMC, as established by NLM. The aim of MEDLINE is to provide a highly selective index of journals in biomedical literature. Conversely, $\mathrm{PMC}^{\prime}$ s aim is to provide a permanent archive for good-quality research, so any journal that meets NLM's standards for scientific and editorial quality will be accepted $[8,26]$. Publishing industry best practices are considered for both MEDLINE and PMC [24].

In response to criticisms of the increase in nonbiomedical content deposited in PMC, both Funk and Backus emphasized that PMC provides a vehicle for research efficiency and broader content, while supporting public contributions to scientific research. Numerous funders list PMC as their

Figure 7 PubMed records added from PMC publisher submissions

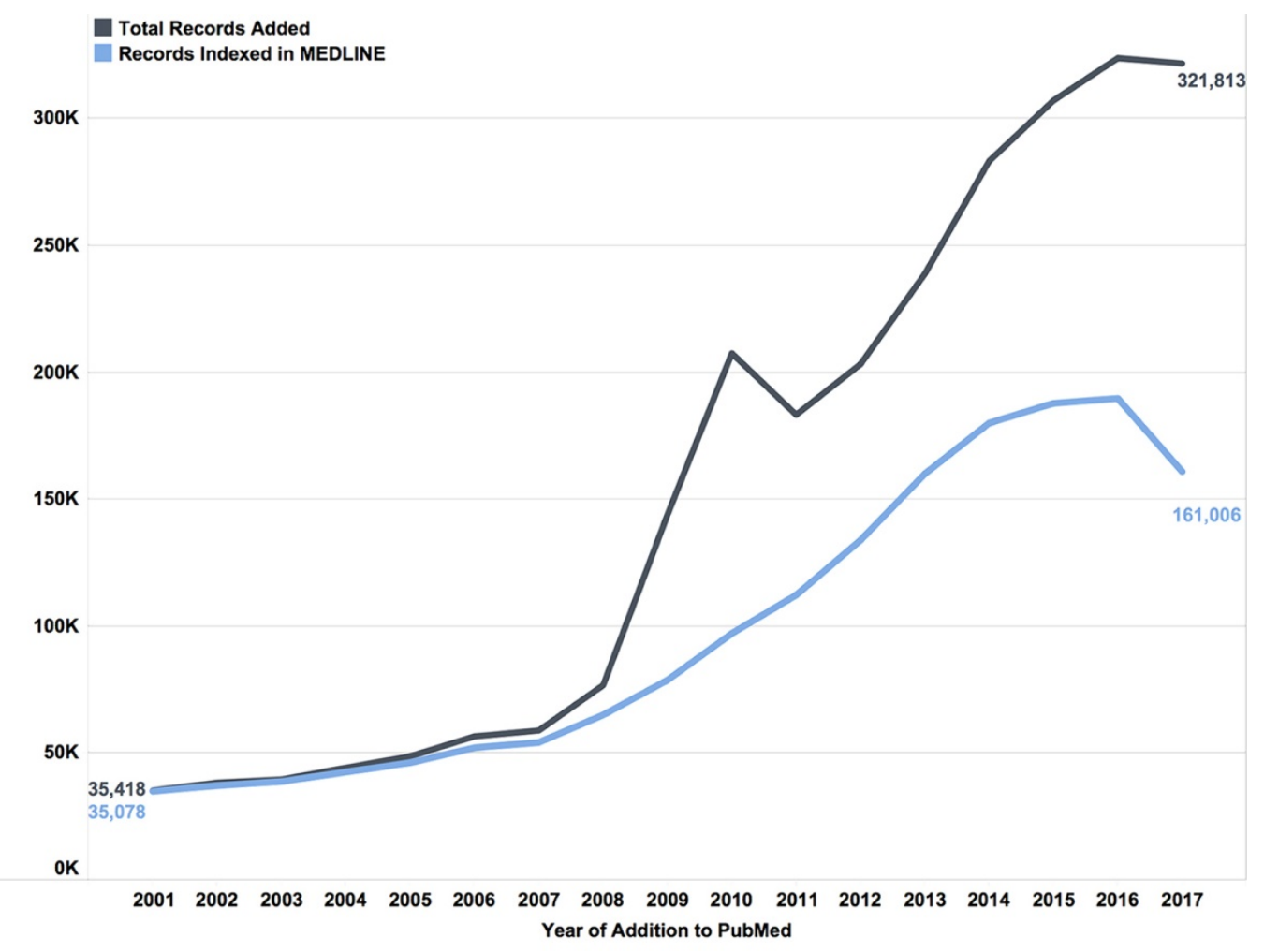

Note: This chart displays records from participating journals' contents and from scanned historical materials. It does not include records from author manuscripts that were submitted by the publisher. 
mandated archive, including the Bill and Melinda Gates Foundation and all Department of Health and Human Services operating divisions (e.g., Centers for Disease Control and Prevention, Food and Drug Administration, and Centers for Medicare and Medicaid Services) [33]. The Department of Homeland Security began using PMC as an archive in 2018 [25]. Funk stated that including this nonbiomedical content has value: some people might not easily find the literature if it is not included in the archive, and it is helpful for science to be less siloed, as there is some overlap between research domains [25]. For example, research occurring on the space station is beneficial to the biomedical community's understanding of different aspects of human health [25].

\section{Ongoing quality control}

In the interviews, Steinke, Backus, and Funk mentioned the reevaluation processes that occur for MEDLINE and PMC. Sometimes poor-quality journals exist in both resources because no process is perfect. Also, the quality of journals can change over time, reflecting changes in editorial leadership or publishers. Reviews have occurred for MEDLINE since LSTRC was formed in 1988, but these reviews typically centered on a specific topic. For example, the American Hospital Association and American Dental Association recommended journals in specific areas. This topic-centered approach had not occurred in recent years, but a publication that has been included in MEDLINE can be reviewed if issues are noted with publication quality, production problems, or nonconformance with industry best practices [25,26].

PMC has had an informal reevaluation process for years, but a more formal process was implemented in 2017 [25]. PMC journal managers perform ongoing quality assessment of features like the volume of content produced by journals and changes in journal practices. PMC staff also keep up with user reports of systemic problems and comments that are made about a resource through online conversations [25]. If there are verifiable concerns about the scientific or editorial quality of the content in a PMC journal or significant changes in its ownership, policies, or practices, a journal may undergo another review. Before a reevaluation begins, NLM staff will notify the journal of the concerns and place a hold on processing new content during the review. The reevaluation process is similar to the review process for new journal applications, including evaluation by external consultants, and the decision to continue or discontinue archiving journal content in PMC is final [17].

\section{DISCUSSION}

The diminishing percentage of MEDLINE-indexed records in PubMed is likely due to PMC as a growing component of PubMed. There are criticisms of PMC's inclusion in PubMed, referring to it as a backdoor option for literature that is not indexed in MEDLINE. This "PMC backdoor" is blamed for reducing the quality of PubMed. In a blog post, Michelle Kraft, AHIP, former president of the Medical Library Association, compared PMC manuscripts appearing in PubMed to medical advice from Gwyneth Paltrow's Goop site being published on WebMD [40].

However, author manuscripts are currently the smallest percentage of PMC content (12\%) and an even smaller component of PubMed $(<2 \%)$. In addition, most manuscripts deposited by authors in PMC are published in MEDLINE-indexed journals, and this rate has remained high over time. Because the majority of manuscripts deposited by authors in PMC come from MEDLINE-indexed journals, it could be argued that the funding agencies' grant review process provides some quality control for author manuscripts in PMC. Funk also stated a similar claim in the interview [25]. However, we reiterate that inclusion in MEDLINE does not guarantee good scientific methods to users searching for research. Likewise, authors should still critically assess publication venues and make good choices in determining where to publish, especially when they submit articles from funded research, because predatory publishers can make readers question research results.

In regard to journal submissions, the rate of additions coming from publishers is increasing, likely due to an interest in participating in the movement toward more open research that is reflected by authors' publishing habits and public access mandates. However, any journal that is not indexed in MEDLINE with a formal agreement to deposit in PMC must go through a review process 
first. This review process has become more stringent in recent years. There is also a formal reevaluation process to address problem journals that have already been accepted.

As the scholarly environment continues to change and research is available through interfaces that interact with thousands of journals, it is important to evaluate an article on its own merit in addition to evaluating the publication as a whole. This issue is not unique to PubMed, with researchers having previously found some potentially predatory journal titles in other databases, including the Directory of Open Access Journals and Academic Search Complete [46-48].

Librarians advise users on distinguishing quality research through critical appraisal and assist authors in searching for and choosing reputable publishers. Most use a number of tools in this process. NLM encourages users to visit the NLM Catalog for additional information about journals in PubMed, including their indexing status (MEDLINE or non-MEDLINE), their selection for the NLM collection, and their participation in PMC [16, 49]. In addition, NIH offers recommendations for resources to evaluate journals, such as using Think Check Submit and becoming familiar with publishing best practices [32]. Multiple publications also explain how to critically read and evaluate the quality of scientific research at the article level [50-52].

\section{Distinguishing resources in PubMed}

In regard to PubMed and the various resources it encompasses, it would be beneficial for users if NLM provided a clearer indication from which particular resources a record stems. It can be confusing to navigate the different types of content in PubMed, especially because there is so much overlap. Many people view a journal's inclusion in MEDLINE as a credential that weighs in a journal's favor because of the LSTRC review methods, even though PMC journals are also evaluated for scientific quality. Users still want the ability to filter results based on whether records are indexed in MEDLINE. Currently, the status of the different record types in PubMed is somewhat buried in the search results. There are no visible tags for other statuses (e.g., in process or publisher-supplied) available on the search results page, and the status tag [Indexed for MEDLINE] is only visible in the abstract view. Previously, this status was available in the summary view.

There are multiple ways to search PubMed for MEDLINE-only citations, including by using solely $\mathrm{MeSH}$ terms in a search strategy, using the MEDLINE filter on the search results page, adding the medline[sb] tag to a search strategy, or searching MEDLINE through a licensed vendor interface. However, limiting a search to only MEDLINE records often excludes the most current research, as many articles are still in-process due to the indexing backlog. As NLM develops a solution for the backlog, it may become easier to search MEDLINE, but it is crucial for users to note that PMC also includes quality research and is providing increasing public access to literature that might otherwise be behind paywalls.

\section{Limitations}

Our findings are only as accurate as the retrieval of results using the NCBI PubMed interface, and the numbers reflect what was displayed in the results of search strategies that we developed and that NLM did not validate. There was also a discrepancy between totals when searching all[sb] in PMC and pubmed pmc[sb] or pubmed pmc all[sb] in PubMed, likely due to a small collection of PMC records that were not included in PubMed. It is also possible that some records were added to PubMed through MEDLINE before the full text was deposited in PMC in a different year. In addition, some PubMed records are still in the "publisher supplied" status, which means that they were recently added by the publisher, but NLM staff have not yet distinguished whether they will eventually be indexed in MEDLINE.

\section{CONCLUSION}

The percentage of MEDLINE records in PubMed has been slowly decreasing; however, whether that trend will continue and the meaning and effect of this shift is not clear. Further research is necessary to investigate the impact of the increase in PMC content, especially the impact of the new review policies and the contributions of journals that fully participate, on the role of PubMed for users who are searching for literature and for authors who are attempting to seek validation for publications in which to publish. In addition, there is a lack of 
studies investigating the research quality of literature retrieved through PubMed as well as other resources, using proven critical appraisal methods rather than comparisons with lists of journals and publishers, like those created by Beall. Research of this caliber will support librarians' efforts to encourage users to engage in the same types of evaluations when searching for literature and choosing where to submit research articles.

\section{ACKNOWLEDGMENTS}

The authors thank Dr. Angela Liegey-Dougall for her assistance with our statistical analysis methods. We also thank NLM staff and Dr. Laurey Steinke for providing information for our investigation.

\section{DATA AVAILABILITY STATEMENT}

Data associated with this article are available in the Texas Data Repository Dataverse <DOI: http://dx.doi.org/10.18738/T8/XTYSHI>.

\section{REFERENCES}

1. Marill JL. Journal selection at the National Library of Medicine: a new process for challenging times. Technicalities [Internet]. 2016 Jul/ Aug;36(4):1-5 [cited 26 Oct 2018].

<https://www.nlm.nih.gov/pubs/staffpubs/lo/TECH_V3 6_N4_JulAug16_Marill.pdf $>$.

2. De Groote SL, Shultz M, Blecic DD. Information-seeking behavior and the use of online resources: a snapshot of current health sciences faculty. J Med Libr Assoc. 2014 Jul;102(3):169-76. DOI: http://dx.doi.org/10.3163/15365050.102.3.006.

3. Cogdill KW, Friedman CP, Jenkins CG, Mays B, Sharp MC. Information needs and information seeking in community medical education. Acad Med. 2000 May;75(5):484-6. DOI: http://dx.doi.org/10.1097/00001888-200005000-00020.

4. Quesenberry AC, Oelschlegel S, Earl M, Leonard K, Vaughn CJ. The impact of library resources and services on the scholarly activity of medical faculty and residents. Med Ref Serv Q. 2016 Jul-Sep; 5(3):259-65. DOI: http://dx.doi.org/10.1080/02763869.2016.1189778.

5. Dunn K, Marshall JG, Wells AL, Backus JEB. Examining the role of MEDLINE as a patient care information resource: an analysis of data from the Value of Libraries study. J Med Libr Assoc. 2017 Oct;105(4):336-46. DOI: http://dx.doi.org/10.5195/jmla.2017.87.

6. Ketchum AM. The research life cycle and the health sciences librarian: responding to change in scholarly communication. J Med Libr Assoc. 2017 Jan;105(1):80-3. DOI: http://dx.doi.org/10.5195/imla.2017.110.
7. Mears K, Bandy SL. Investigating the need for scholarly communications positions in Association of Academic Health Sciences Libraries member institutions. J Med Libr Assoc. 2017 Apr;105(2):145-9. DOI: http://dx.doi.org/10.5195/jmla.2017.208.

8. National Library of Medicine. MEDLINE®: description of the database [Internet]. The Library; 2004 [cited 26 Oct 2017]. <https:// www.nlm.nih.gov/bsd/medline.html>.

9. Lindberg DAB. Internet access to the National Library of Medicine. Eff Clin Pract. 2000 Sep/Oct;4:256-60 [cited 26 Oct 2017]. <http:/ / ecp.acponline.org/sepoct00/nlm.htm>.

10. Canese K, Weis S. PubMed: the bibliographic database. In: The NCBI handbook [Internet]. 2nd ed. Bethesda, MD: National Center for Biotechnology Information (US); 9 Oct 2002 [updated 20 Mar 2013; cited 26 Oct 2018]. <https://www.ncbi.nlm.nih.gov/books/NBK153385>.

11. National Library of Medicine. Free web-based access to NLM databases. NLM Tech Bull [Internet]. 1997 MayJun;296 [cited 26 Oct 2018].

<https://www.nlm.nih.gov/pubs/techbull/mj97/mj97_w eb.html $>$.

12. Canese K. PubMed celebrates its 10th anniversary! NLM Tech Bull [Internet]. 2006 Sep-Oct;(352):e5 [cited 26 Oct 2018].

<https://www.nlm.nih.gov/pubs/techbull/so06/so06_p $\underline{\mathrm{m} \_10 . h t m l}>$.

13. National Library of Medicine. PubMed ${ }^{\circledR}:$ MEDLINE $^{\circledR}$ retrieval on the World Wide Web [Internet]. The Library; 2017 [cited 18 Mar 2018]. <https://www.nlm.nih.gov/bsd/pubmed.html>.

14. National Library of Medicine. FAQ: journal selection for MEDLINE $^{\circledR}$ indexing at NLM [Internet]. The Library; 2017 [cited 26 Oct 2018]. <https://www.nlm.nih.gov/lstrc/i_sel_faq.html>.

15. National Library of Medicine. PMC overview [Internet]. The Library; 2011 [cited 26 Oct 2017]. <https://www.ncbi.nlm.nih.gov/pmc/about/intro/>.

16. Funk K, Stanger R, Eannarino J, Topper L, Majewski K. PubMed journal selection and the changing landscape of scholarly communication [Internet]. National Library of Medicine; 6 Oct 2017 [cited 26 Oct 2017]. <https://www.nlm.nih.gov/bsd/disted/video/selection.h tml>.

17. Minter C. Personal communication with Melanie Modlin (Deputy Director/Public Liaison Officer, National Library of Medicine). 2 Jan 2018.

18. National Library of Medicine. MEDLINE journal selection [Internet]. The Library; 2017 [cited 26 Oct 2018]. <https:/ / www.nlm.nih.gov/lstrc/jsel.html>.

19. National Institutes of Health. Public access policy details [Internet]. The Institutes; 2016 [cited 1 Jan 2018]. <https://publicaccess.nih.gov/policy.htm>.

20. US Congress. Omnibus Appropriations Act, 2009 [Internet]. The Congress; 2009 [cited 1 Jan 2018]. $<$ https://www.congress.gov/111/plaws/publ8/PLAW111publ8.pdf>. 
DOI: dx.doi.org/10.5195/jmla.2019.433

21. National Library of Medicine. PMC and research funder policies [Internet]. The Library; 2018 [cited 26 Oct 2018]. $<$ https://www.ncbi.nlm.nih.gov/pmc/about/publicaccess $>$.

22. National Library of Medicine. PMC FAQs [Internet]. The Library; 2015 [cited 14 Nov 2017]. <https://www.ncbi.nlm.nih.gov/pmc/about/faq/>.

23. National Library of Medicine. PMC policies [Internet]. The Library [cited 9 Jul 2018].

<https://www.ncbi.nlm.nih.gov/pmc/about/guidelines/>.

24. National Library of Medicine. The collection development policy of the NLM. In: Collection development manual of the National Library of Medicine [Internet]. 4th ed. Bethesda, MD: The Library, National Institutes of Health, US Department of Health and Human Services; 2004 [cited 26 Oct 2018].

<http://www.nlm.nih.gov/tsd/acquisitions/cdm/>.

25. Minter CIJ, Ossom Williamson P. Personal communication with Joyce Backus (Associate Director for Library Operations, National Library of Medicine) and Kathryn Funk (Program Specialist for PubMed Central, National Library of Medicine). 2 Jan 2018.

26. Minter CIJ, Ossom Williamson P. Personal communication with Laurey Steinke (Assistant Professor of Biochemistry and Molecular Biology, University of Nebraska Medical Center). 11 Dec 2017.

27. Coleman J. NLM to discontinue PubMed Health on October 31, 2018 [Internet]. NLM Tech Bull [Internet]. 2018 MayJun;(422):e3 [cited 29 Oct 2017]. <https://www.nlm.nih.gov/pubs/techbull/mj18/mj18_p mh_discontinue.html>.

28. National Library of Medicine. About MedlinePlus [Internet]. The Library; 2017 [cited 29 Oct 2017]. <https://medlineplus.gov/aboutmedlineplus.html>.

29. Holdren J. Memorandum for the heads of executive departments and agencies: increasing access to the results of federally funded scientific research [Internet]. Office of Science and Technology Policy; 22 Feb 2013 [cited 18 Mar 2018]

$<$ https://obamawhitehouse.archives.gov/sites/default/fil es/microsites/ostp/ostp_public_access_memo_2013.pdf $>$.

30. McCann TV, Polacsek M. False gold: safely navigating open access publishing to avoid predatory publishers and journals. J Adv Nurs. 2018 Apr;74(4):809-17. DOI: http://dx.doi.org/10.1111/jan.13483.

31. Lake L; Federal Trade Commission. Academics and scientists: beware of predatory journal publishers [Internet]. The Commission; 26 Aug 2016 [cited 26 Oct 2017]. <https://www.consumer.ftc.gov/blog/2016/08/academic s-and-scientists-beware-predatory-journal-publishers $>$.

32. National Institutes of Health. Statement on article publication resulting from NIH funded research. Notice number: NOT-OD-18-011 [Internet]. The Institutes; 3 Nov 2017 [cited 20 Dec 2017]. $<$ https://grants.nih.gov/grants/guide/notice-files/NOTOD-18-011.html>.
33. Blank D, Buchweitz C, Procianoy RS. Impact of SciELO and MEDLINE indexing on submissions to Jornal de Pediatria. J Pediatr. 2005 Nov/Dec;81(6):431-4. DOI: http://dx.doi.org/10.2223/JPED.1414.

34. Maggio LA, Moorhead LL, Willinsky JM. Qualitative study of physicians' varied uses of biomedical research in the USA. BMJ Open. 2016;6(11):e012846. DOI: http://dx.doi.org/10.1136/bmjopen-2016-012846.

35. Chua S, Qureshi AM, Krishnan V, Pai DR, Kamal LB, Gunasegaran S, Afzal MZ, Ambawatta L, Gan JY, Kew PY, Winn T, Sood S. The impact factor of an open access journal does not contribute to an article's citations. F1000Research. 2017;6:208. DOI: http://dx.doi.org/10.12688/f1000research.10892.1.

36. Hua F, Sun H, Walsh T, Glenny AM, Worthington H. Open access to journal articles in oncology: current situation and citation impact. Ann Oncol. 2017 Oct 1;28(10):2612-7. DOI: http://dx.doi.org/10.1093/annonc/mdx398.

37. Manca A, Martinez G, Cugusi L, Dragone D, Dvir Z, Deriu $F$. The surge of predatory open-access in neurosciences and neurology. Neurosci. 2017 Jun 14;20:166-73. DOI: http://dx.doi.org/10.1016/j.neuroscience.2017.04.014

38. Manca A, Martinez G, Cugusi L, Dragone D, Mercuro G Deriu F. Predatory open access in rehabilitation. Arch Phys Med Rehabil. 2017 May;98(5):1051-6. DOI: http://dx.doi.org/10.1016/j.apmr.2017.01.002

39. Anderson K. A confusion of journals - what is PubMed now? Scholarly Kitchen [Internet]. 7 Sep 2017 [cited 29 Oct 2017].

<https://scholarlykitchen.sspnet.org/2017/09/07/confusi on-journals-pubmed-now $/>$.

40. Kraft M. PubMed's backdoor makes me question quality. Krafty Librarian [Internet]. 15 Jun 2017 [cited 29 Oct 2017]. <http://www.kraftylibrarian.com/pubmeds-backdoormakes-me-question-quality $>$.

41. Berger M, Cirasella J. Beyond Beall's List: better understanding predatory publishers. Coll Res Libr News. 2015 Mar;76(3):132-5. DOI: http://dx.doi.org/10.5860/crln.76.3.9277.

42. Smith C, Afshar AS. Wolf in the fold: quality of databases and digital repositories post-Beall's List [Internet]. Presented at MLA '18, 118th MLA Annual Meeting; Atlanta, GA; 21 May 2018 [cited 15 Jun 2018]. <https:// www.eventscribe.com/2018/MLA/fsPopup.asp? Mode=presInfo\&PresentationID $=367225>$

43. National Center for Biotechnology Information. PubMed help: subset [Internet]. The Center; 2017 Nov 27 [cited 31 Dec 2017].

<https://www.ncbi.nlm.nih.gov/books/NBK3827/\#pubm edhelp.Subset_SB>.

44. National Library of Medicine. Index section [Internet]. The Library; 8 Aug 2016 [cited 11 Jan 2018]. <https://www.nlm.nih.gov/bsd/indexhome.html>.

45. National Library of Medicine. Indexing initiative [Internet]. The Library; 29 Sep 2016 [cited 11 Jan 2018]. <https://ii.nlm.nih.gov/MTI/index.shtml>. 
46. Marchitelli A, Galimberti P, Bollini A, Mitchell D. Helping journals to improve their publishing standards: a data analysis of DOAJ new criteria effects. Italian J Libr Arch Inf Sci. 2017;8(1):1-21. DOI: http:// dx.doi.org/10.4403/jlis.it12052.

47. Shen C, Björk BC. 'Predatory' open access: a longitudinal study of article volumes and market characteristics. BMC Med. 2015 Oct 1;13:230. DOI:

http://dx.doi.org/10.1186/s12916-015-0469-2.

48. Nelson N, Huffman J. Predatory journals in library databases: how much should we worry? Ser Libr. 2015;69(2):169-92. DOI: http://dx.doi.org/10.1080/0361526x.2015.1080782.

49. Marill J. Catalog display changes for journal titles not in the NLM collection. NLM Tech Bull [Internet]. 2018 JanFeb;(420):e1 [cited 26 Oct 2018].

<https://www.nlm.nih.gov/pubs/techbull/if18/if18_noc_ serials_display_change.html>.

50. Hudson-Barr D. How to read a research article. J Spec Pediatr Nurs. 2004 Apr-Jun;9(2):70-2. DOI:

http://dx.doi.org/10.1111/j.1088-145X.2004.00070.x.

51. Hart DL, Poston II WR, Perry JF. Critically reading a research article. J Orthop Sports Phys Ther. 1980;2(2):72-6. DOI: http://dx.doi.org/10.2519/jospt.1980.2.2.72.

52. Vickers A. Critical appraisal: how to read a clinical research paper. Complement Ther Med. 1995 Jul;3(3):158-66. DOI: http://dx.doi.org/10.1016/S0965-2299(95)80057-3.

\section{SUPPLEMENTAL FILE}

- Appendix: Formulas used by the authors to perform their statistical analyses

\section{AUTHORS' AFFILIATIONS}

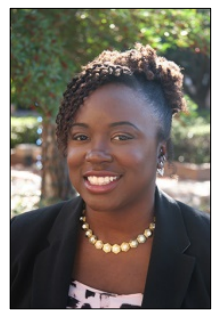

Peace Ossom Williamson, MLS, MS, AHIP, peace@uta.edu, http://orcid.org/0000-00016229-7514, Director for Research Data Services, Libraries, University of Texas at Arlington, 702 Planetarium Place, Box 19497, Arlington, TX 76019

Christian I. J. Minter, MSLIS,

christian.minter@unmc.edu,

http://orcid.org/0000-0002-6026-5858, Community Engagement and Health Literacy Librarian, McGoogan Library of Medicine, University of Nebraska Medical Center, 986705 Nebraska Medical Center, Omaha, NE 68198-6705

Received January 2018; accepted July 2018

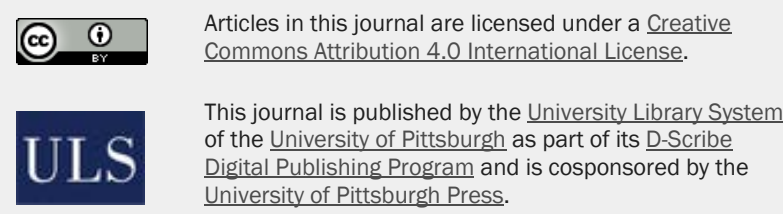

ISSN 1558-9439 (Online) 